RESEARCH ETHICS

\title{
The influence of risk and monetary payment on the research participation decision making process
}

\author{
J P Bentley, P G Thacker
}

See end of article for authors' affiliations

.....................

Correspondence to: J P Bentley, Faser Hall 219A, School of Pharmacy, The University of Mississippi, University, MS 38677, USA; phipb@olemiss.edu

Received

5 September 2002

Revised version received

8 February 2003

Accepted for publication

17 March 2003
J Med Ethics 2004;30:293-298. doi: 10.1136/jme.2002.001594

Objectives: To determine the effects of risk and payment on subjects' willingness to participate, and to examine how payment influences subjects' potential behaviours and risk evaluations.

Methods: A 3 (level of risk) $\times 3$ (level of monetary payment), between subjects, completely randomised factorial design was used. Students enrolled at one of five US pharmacy schools read a recruitment notice and informed consent form for a hypothetical study, and completed a questionnaire. Risk level was manipulated using recruitment notices and informed consent documents from hypothetical biomedical research projects. Payment levels were determined using the payment models evaluated by Dickert and Grady as a guide. Five dependent variables were assessed in the questionnaire: willingness to participate, willingness to participate with no payment, propensity to neglect to tell about restricted activities, propensity to neglect to tell about negative effects, and risk rating.

Results: Monetary payment had positive effects on respondents' willingness to participate in research, regardless of the level of risk. However, higher monetary payments did not appear to blind respondents to the risks of a study. Payment had some influence on respondents' potential behaviours regarding concealing information about restricted activities. However, payment did not appear to have a significant effect on respondents' propensity to neglect to tell researchers about negative effects.

Conclusions: Monetary payments appear to do what they are intended to do: make subjects more willing to participate in research. Concerns about payments blinding subjects to risks could not be substantiated in the present study. However, the findings do raise other concerns-notably the potential for payments to diminish the integrity of a study's findings. Future research is critical to make sound decisions about the payment of research subjects.
A lthough the practice of paying subjects to participate in research is not new, it continues to serve as a point of debate for many members of the research community. Among other issues, some are concerned that the use of such tactics could induce subjects into taking part in a study that they would not participate in otherwise (by blinding prospective subjects to risks) or cause subjects to conceal information that would disqualify them from the study. Although there is considerable debate from normative ethical perspectives concerning undue inducement of potential research subjects with monetary payments, there are few empirical data regarding the effects of monetary payments. Will varying levels of monetary payments have the same effect on willingness to participate at varying levels of risk? Will monetary payments lead subjects to conceal information that would disqualify them from the study? Will varying levels of monetary payments lead to different ratings of risk of the same study? Most authors have made empirical claims without testing these issues. This research was undertaken to add to the discussion concerning the payment of research subjects by providing empirical data on the potential effects of monetary payments.

\section{LITERATURE REVIEW}

After distinguishing coercion from inducement, this section explores both normative ethical arguments and the empirical literature surrounding the topic of paying research subjects.

\section{Coercion versus inducement}

Faden and Beauchamp ${ }^{1}$ define coercion as "an extreme form of influence by another person that completely controls a person's decision". They further state that such an influence "deprives the person of autonomous choice, and thus is incompatible with informed consent". Most authors agree that coercion requires a credible threat of severe negative

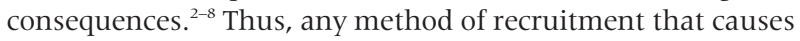
a person to participate (assuming they do not want to) through the use of intended, credible, and severe threatssuch that the person has no other alternative but to participate-would be considered coercive.

Monetary payments are often used as inducements; they motivate people to do something. Inducements are offers, not threats, ${ }^{68}$ and therefore they are not usually considered to be coercive (although there are notable exceptions: see reference $^{6}$ for an example). Although inducements in most instances are not considered to be coercive, it has been suggested that inducements can be undue, ${ }^{29}$ exploitative, ${ }^{457}$ or morally impermissible. ${ }^{45}$ Thus, "a monetary inducement can invalidate informed consent without being coercive" ${ }^{10}{ }^{10}$

Macklin ${ }^{2}$ notes that the concept of inducement is weaker than the notion of coercion and draws a conceptual distinction between due and undue inducement. She describes one paradigm for undue inducement as whether the inducement leads subjects to lie, deceive, or conceal information that would exclude them from the study if known to investigators. It is not the dollar amount alone that determines what is an undue inducement ${ }^{2}$; the impoverishment of subjects and the risk of injury from the study are also considerations. ${ }^{3}$

\section{Positions on inducements}

The common and long practised act of paying research subjects $^{811-13}$ to aid recruitment and retention is seen by

Abbreviations: IRB, institutional review board; PCA, principal
components analysis; SES, socioeconomic status. 
some as unethical. For example, McNeill states that monetary inducements encourage people to expose themselves to risk and may add to a subject's difficulties in assessing the apparent level of risk of a study. ${ }^{14}$ Furthermore, McNeill argues that "the reason that inducement is particularly of concern is that those most susceptible to inducement may be the least able to assess the aims and technical information relating to the research". ${ }^{15}$ He maintains that inducements increase inequity in the research process because the majority of research participants are of lower socioeconomic status (SES) while higher SES people typically benefit from such research. Macklin also discusses the equitable distribution of society's benefits and burdens with respect to research, noting that the lower the payment (with the goal being to avoid undue influence) the greater the likelihood for volunteers to be of lower SES. ${ }^{2}$

To McNeill, any offer of payment when a research study involves risk of injury is objectionable. ${ }^{14}$ However, Macklin reasons that some level of inducement is necessary to prompt a sufficient number of people to volunteer. ${ }^{2}$ Her recommendation is to set initial payments low for normal, healthy volunteers (to avoid undue inducement). While this may lead to a greater likelihood of volunteers coming from lower socioeconomic groups, she argues there is no way to avoid this objection from social justice, given the moral precept of pay equity.

Although some argue that subjects should not be paid or that the payments to subjects should be minimised, others claim that payments to research subjects are appropriate and some go further to argue that there should be no restrictions as to how much is offered. For example, Brody ${ }^{16}$ states that "if the independent review panel has already concluded that the risk:benefit ratio of the research is acceptable (otherwise, the research could not be approved), how can the large payment harm the subject? And in what way are large payments for acceptable research coercive or exploitative?" While Palmer ${ }^{17}$ appears to agree with Brody in most cases, he concludes that "concern about excessive payment is warranted only under stringent conditions ... In research involving the highest acceptable risk, offers of large payment may cause vulnerable persons to lose the freedom to refuse participation." Thus, according to Palmer, inducements can be undue only in those research studies that involve the highest acceptable risk of physical or psychological injury. Monetary inducements could also be considered undue for research that presents unreasonable risk-for example, death-but Palmer argues that institutional review boards (IRBs) would not approve these. Even McNeill, who appears to argue strongly against the use of monetary inducements in clinical trials, concedes that when there is no known or very little likelihood of harm, monetary inducement may be justifiable. ${ }^{14}$

Wilkinson and Moore examine arguments against inducement including: inducements undermine consent; inducements can damage the welfare of participants; inducements exploit research subjects, especially the poor; and inducements can result in subject selection bias. ${ }^{6}$ After discussing what they consider to be the strongest case they could develop for each of these arguments, they conclude that with one possible single exception, each of these arguments against inducement is unpersuasive. The one problem case involves studies that have at least one harm related exclusion criterion (for example, subjects with heart conditions cannot participate) and no adequate method-independent of subject self report-for researchers to verify that potential subjects meet the exclusion criterion. In this case, monetary inducements might entice subjects who are "financially hard pressed" to lie or conceal information in order to participate in a study to receive the payment and researchers cannot adequately verify the accuracy of the subject reported information. Wilkinson and Moore conclude that in this case, and only in this case, inducements should create problems for ethics committees. ${ }^{6}$ They further argue, however, that ethics committees should probably not even allow these types of studies to proceed in the first place, regardless of the offering of any inducement.

In a subsequent paper, Wilkinson and Moore address three additional objections to inducements: inducements create greater inequity, inducements crowd out less funded research, and inducements undesirably commercialise the research process. ${ }^{18}$ They argue that there is a pro tanto reason to allow subjects to be paid, which they define as freedom to contract, which stipulates that "the relationship between researcher and subject should be a matter of agreement between them". As in their first paper, Wilkinson and Moore analyse each anti-inducement argument for justification and conclude that each is insufficient to outweigh their freedom of contract position. ${ }^{18}$

\section{Empirical findings}

Thus, taking different normative ethical perspectives, several authors have argued both for and against the use of monetary payments to research subjects. From an empirical perspective, some researchers have examined subjects' motivations for research participation, including the role of monetary payments. Some studies have shown that some healthy volunteers do not agree with paying subjects. ${ }^{19}$ Other studies have shown that financial motives are less important than other motivations ${ }^{20}$ and that economic gain is rarely the sole motivation for research. ${ }^{21}$ However, several studies have pointed to financial payment as a very significant if not the most significant influence on the decision to participate in research, especially for healthy volunteers. ${ }^{22-24}$

Another empirical approach that has recently generated some findings has been to ask respondents directly if a monetary payment would impair their own, and others' ability to think carefully about risks and benefits of a study. ${ }^{25}$ Using such a method, Casarett et al found that a large percentage of individuals believe that a US\$500 payment would impair others' judgment, but a significantly smaller number believe that the payment would impair their own. ${ }^{25}$ The authors conclude that concerns about the influence of payments for research are expressed by members of the general public, not just ethicists.

The available empirical studies suggest there is potential for misconduct by researchers to offer payments in such excess that they could be considered undue in some circumstances. Given this potential, how does one determine what an appropriate level of payment is?

\section{Models and guidelines}

Although federal guidelines allude to the potential ethical difficulties arising from payment to research subjects, they offer little meaningful guidance to researchers and IRBs for how to pay subjects. ${ }^{11}{ }^{12}{ }^{26}$ In addition, while organisations that conduct and review human subjects research often engage in (or allow) the payment of subjects, few have written policies on payment. ${ }^{12}$

Macklin argues to set initial payments low for normal, healthy volunteers. ${ }^{2}$ If such a payment does not render the necessary amount of participants, Macklin suggests that the researcher review the risks associated with the study as well as subjects' time requirements to determine whether these played a factor in the under recruitment of subjects. However, how does one determine the initial payment rate? Dickert and Grady have addressed such a question by evaluating three models for the payment of subjects. ${ }^{11}$ In the market model, payment is justified by the need for 
monetary incentives to recruit subjects. Payment in this model is based solely upon the economic principle of supply and demand, and advocates the use of completion bonuses as well as other incentives for compliance with the protocol. The second model evaluated by the authors is the wage payment model. In this model, payment is rendered on the premise that research participation requires little skill but demands time and effort from the subject. Thus, payment using this model is based solely on standard wage payment for unskilled labour with additional payments being made for uncomfortable procedures. The third payment model, the reimbursement model, justifies payment by using the premise that research subjects should not be required to suffer financial sacrifice. Therefore, subjects are reimbursed for expenses incurred and may be paid for lost wages. Such a model could lead to the unequal payment of subjects for the same amount of participation, as a subject who makes more per hour at his or her normal occupation or profession would receive more compensation.

Dickert and Grady ${ }^{11}$ recommend the adoption of the wage payment model for three reasons: (1) it reduces undue inducement concerns, (2) it standardises payment schedules, and (3) it establishes a system in which payment is based on the contribution subjects make, consistent with the principle of equal pay for equal work. Their recommendation is primarily based on normative ethical evaluation rather than empirical evidence. Indeed, at the end of their manuscript, Dickert and Grady ${ }^{27}$ suggest that "there is a need for empirical research to determine the ways in which offers of money affect the quality of subjects' informed consent ... there is a need for data on the importance of payment with respect to successful recruitment; little is known about the effect of different amounts or methods of payment on recruitment efforts." In a subsequent article, Dickert et al ${ }^{28}$ note that, "further study and discussion are needed to understand when money is an undue influence, as well as the impact of payment on subject selection and scientific integrity".

\section{RESEARCH OBJECTIVES}

The objectives of this study were to determine the effects of risk and monetary payment on subjects' willingness to participate and to examine how payment influences subjects' potential behaviours and risk evaluations. Although monetary payments have been shown to increase the response rate in mail surveys (for example, see reference 29), there is minimal risk associated with most surveys. In this study, we manipulated levels of monetary payment and risk within the context of a single design to assess the effects of these variables on the research participation decision making process. We are not aware of other published studies that have used such a design.

\section{METHODS}

\section{Independent variables}

The study used a 3 (level of risk) $\times 3$ (level of monetary payment), between subjects, completely randomised factorial design. Risk level was manipulated using recruitment notices and informed consent documents from hypothetical biomedical research projects. The high risk level was a phase I drug trial for a drug that has not yet been tested in humans. The medium risk level was a bioequivalence study for a generic version of a brand name drug that is already on the market. The low risk level was a study that measured salivary levels of two stress hormones of healthy volunteers to compare with subjects who have had heart attacks (no drug is ingested/no blood is drawn). Federal sources ${ }^{930} 31$ and examples of documents used in actual studies guided construction of the informed consent forms and recruitment notices. Also, coordinators from two different IRBs reviewed the documents. Studies for all three risk levels were designed for healthy volunteers, and the amount of time required of subjects for each study was held constant. Quantitative pretests $(\mathrm{n}=30$ for each level) indicated significantly different risk ratings among the three risk levels.

Payment levels were determined using the payment models evaluated by Dickert and Grady as a guide. ${ }^{11}$ The total amount of time required for the three hypothetical studies was estimated at about 54 hours (two 24 hour stays and 12 half hour sessions). For the highest level of payment, a rate of $\$ 28$ per hour was used and $\$ 300$ was added as an additional risk based bonus, for a total payment of $\$ 1800$. For the medium level of payment, a rate of $\$ 14$ per hour (slightly below the May 2001 total national average for non-farm production workers ${ }^{32}$ ) was used and $\$ 50$ was added as an additional risk based bonus, for a total payment of $\$ 800$. For the lowest level of payment, only parking costs $(\$ 3.00$ per hour) and travel costs ( $\$ 0.345$ per mile-an average of 40 miles per day) were used, for a total of $\$ 350$. Neither the recruitment notice nor the informed consent form specified how these amounts were calculated; respondents were merely made aware of how much they would be paid for participation. The following language was used in the informed consent form under the heading "Payment":

"In return for your time, effort and travel expenses, you will be paid \$XXX for your participation in this study. If you do not complete the study, you will be paid on a pro-rated basis that is calculated based on the time you have contributed to the study. A check will be mailed to you approximately six weeks after your participation in the study has ended."

\section{Sample and data collection}

Each recruitment notice/informed consent form (used to manipulate risk) was paired with each of the three payment levels yielding a total of nine treatment groups. Power analysis indicated that 23 cases per treatment group $(n=207)$ were necessary to have power of 0.80 to detect medium main and interaction effects with a significance level of 0.05. Packets containing an explanation letter, a copy of one of the recruitment notices/informed consent forms, and a questionnaire were randomly distributed through course instructors to pharmacy students at five different universities. In the explanation letter, students were asked to read a recruitment notice and informed consent form for a hypothetical research study, complete an anonymous questionnaire, and return all materials to their instructor; all tasks were performed outside of class time (no incentive was provided for returning the questionnaire). Each student was exposed to only one risk level/payment level combination and an equal number of packets in each treatment group were sent to each school. Students were asked to not discuss their responses or what they read with other students.

\section{Dependent measures}

The questionnaire was designed to assess five dependent variables (table 1 ) in addition to several demographic questions. Respondents were asked to rate their willingness to participate in the hypothetical study with and without the monetary payment on a 10 point scale, with 10 being "I would definitely participate". Respondents were also asked to provide their honest opinion about the likelihood that they would neglect to tell researchers about eight activities that were described as restricted in the informed consent form (such as participation in a clinical trial within the previous 30 days or the consumption of alcohol or caffeine during the study period or 48 hours before the start of the study). Each restriction was rated on a 10 point scale with 10 being "very 
likely to neglect to tell". Similarly, respondents were asked two questions concerning their likelihood to neglect to tell researchers about negative effects that could cause them to be eliminated from the study (for example: side effects; not feeling well). All informed consent forms instructed subjects to report side effects and to advise the medical staff if they were not feeling well. As with the previous construct, a 10 point scale (with 10 being "very likely to neglect to tell") was used. Finally, respondents were asked to evaluate the risk involved in the hypothetical study using a 5 item scale designed to have respondents assess both the likelihood and the severity of negative consequences of participation.

To determine the quality of the three multi-item scales, reliability analysis and principal components analysis (PCA) were used. For each multi-item scale, corrected item-to-total correlations and Cronbach's alpha were calculated to assess the extent to which the set of items in the multi-item scale measure the same attribute (that is, internal consistency reliability). PCA was then conducted to provide some evidence of the unidimensionality of each of the multi-item scales $^{33}$

Cronbach's alpha for each of the multi-item scales can be found in table 1 and all are well above acceptable norms. ${ }^{34}$ Within each of the multi-item scales, correlations between individual items and the scale of interest (corrected item-tototal correlations) exceeded 0.5. PCA results indicated that items in each multi-item scale loaded highly on a single component (loadings greater than 0.6) and did not significantly load on other components. These results support the summation of items in each of the multi-item scales to obtain summated total scores for these three measures. To ease interpretation of the dependent variable scores, these summated scores were divided by the number of items in the scale (thus, all dependent variables were scored on a 1-10 scale). These transformed scores for each multi-item scale were used in all subsequent analyses. A description of the meaning of a higher score for all five dependent variables is provided in table 1 .

\section{Analysis procedure}

Data were analysed using two factor analysis of covariance (ANCOVA) procedures, with a measure of "venturesomeness $^{\prime \prime 35}$ as the covariate. Separate analyses were conducted for each of the five dependent variables.

This study received IRB exemption from the University of Mississippi Institutional Review Board. The study was also submitted to the IRBs at the other four universities where the packets were distributed, and was exempted. Copies of the recruitment notices and informed consent forms used in the manipulation of the independent variables and the data collection instrument used for this study are available upon request.

Table 1 Description of dependent variables

\begin{tabular}{|c|c|c|c|}
\hline Measure & $\begin{array}{l}\text { Number } \\
\text { of items }\end{array}$ & $\alpha$ & Meaning \\
\hline Willingness to participate & 1 & - & $\begin{array}{l}\text { Higher the value, } \\
\text { greater the willingness }\end{array}$ \\
\hline $\begin{array}{l}\text { Willingness to participate } \\
\text { with no payment }\end{array}$ & 1 & - & $\begin{array}{l}\text { Higher the value, } \\
\text { greater the willingness }\end{array}$ \\
\hline $\begin{array}{l}\text { Propensity to neglect to tell } \\
\text { about restricted activities }\end{array}$ & 8 & 0.92 & $\begin{array}{l}\text { Higher the value, } \\
\text { higher the propensity }\end{array}$ \\
\hline $\begin{array}{l}\text { Propensity to neglect to tell } \\
\text { about negative effects }\end{array}$ & 2 & 0.87 & $\begin{array}{l}\text { Higher the value, } \\
\text { higher the propensity }\end{array}$ \\
\hline Risk rating & 5 & 0.96 & $\begin{array}{l}\text { Higher the value, } \\
\text { higher the risk }\end{array}$ \\
\hline
\end{tabular}

\section{RESULTS}

A total of 789 packets were handed out to pharmacy students and 326 were returned. Nine responses were discarded because of missing data and seven were discarded because the respondent's self rated health was not excellent, very good or good, yielding a usable response rate of $39.3 \%$. Due to the nature of the data collection method, cell sizes were not equal. To simplify analysis and interpretation of the results, respondents were randomly discarded from certain cells to achieve equal cell sizes. Given that there was a sufficient number of respondents based on the power analysis conducted before the study, this was determined to be a reasonable alternative. ${ }^{36}$ The final data set comprised 30 respondents per experimental cell $(n=270)$.

Adjusted cell and marginal means for each dependent variable can be found in tables 2 to 6 . No significant first order interactions were noted in any of the analyses. With respect to willingness to participate, both risk level $\left(\mathrm{F}_{(2,260)}=8.90, \mathrm{p}<0.0005\right.$, partial eta $\left.{ }^{2}=0.06\right)$ and monetary payment $\left(\mathrm{F}_{(2,260)}=4.26, \mathrm{p}=0.015\right.$, partial eta $\left.{ }^{2}=0.03\right)$ had a significant effect; with higher levels of risk and lower levels of payment leading to lower willingness ratings. Furthermore, the effect of monetary payment did not appear to vary according to risk level (that is, there was no significant interaction). Without payment, respondents' willingness to participate decreased and their willingness to participate without payment was influenced only by risk level, with higher risk levels leading to lower willingness ratings $\left(\mathrm{F}_{(2,260)}=6.75, \mathrm{p}=0.001\right.$, partial eta $\left.{ }^{2}=0.05\right)$.

Monetary payments appeared to influence respondents' propensity to neglect to tell researchers about restricted activities they have engaged in either before or during a study, with higher payment levels leading to a higher propensity to neglect to tell $\left(\mathrm{F}_{(2,260)}=3.68, \mathrm{p}=0.027\right.$, partial $\left.\mathrm{eta}^{2}=0.03\right)$. However, examination of cell means reveals that this effect may be driven by respondents who were exposed to low and medium risk levels. Risk level appeared to influence respondents' propensity to neglect to tell researchers about experiencing negative effects, with respondents in the low risk group having the highest propensity to neglect to tell $\left(\mathrm{F}_{(2,260)}=3.74, \mathrm{p}=0.025\right.$, partial eta $\left.{ }^{2}=0.03\right)$. Monetary payment did not significantly influence this variable.

There were noticeable differences in risk ratings among the groups exposed to different levels of the risk manipulation $\left(\mathrm{F}_{(2,260)}=275.95, \mathrm{p}<0.0005\right.$, partial eta $\left.{ }^{2}=0.68\right)$; risk rating was not significantly influenced by monetary payment and the effect of risk level on risk rating did not vary by level of monetary payment (that is, there was no significant interaction).

Table 2 Adjusted cell and marginal means (dependent variable: willingness to participate*)

\begin{tabular}{lllll}
\hline & \multicolumn{2}{l}{ Risk level } & \\
\cline { 2 - 4 } Payment level & Low & Medium & High & Row mean \\
\hline$\$ 350$ & 5.67 & 3.99 & 3.86 & $\mathbf{4 . 5 1}^{\mathrm{c}}$ \\
$\$ 800$ & 5.92 & 5.23 & 3.72 & $\mathbf{4 . 9 6}^{\mathrm{c}, \mathrm{d}}$ \\
$\$ 1800$ & 6.50 & 5.87 & 4.95 & $\mathbf{5 . 7 7 ^ { \mathrm { d } }}$ \\
Column mean & $\mathbf{6 . 0 3 ^ { \mathrm { a } }}$ & $\mathbf{5 . 0 3 ^ { \mathrm { a } , \mathrm { b } }}$ & $\mathbf{4 . 1 8 ^ { \mathrm { b } }}$ & \\
\hline
\end{tabular}

*Assessed using a 10 point scale, with 10 being "I would definitely participate"

Significance: the main effects of risk level and payment level are significant $(p<0.05)$

Within the column and row means, means without a common superscript are significantly different at the 0.05 level using Dunn's Method (Bonferroni). 
Table 3 Adjusted cell and marginal means (dependent variable: willingness to participate with no payment*)

\begin{tabular}{lllll}
\hline & \multicolumn{2}{l}{ Risk level } & \\
\cline { 2 - 4 } Payment level & Low & Medium & High & Row mean \\
\hline$\$ 350$ & 2.50 & 1.84 & 1.52 & $\mathbf{1 . 9 5}$ \\
$\$ 800$ & 2.24 & 2.20 & 1.44 & $\mathbf{1 . 9 6}$ \\
$\$ 1800$ & 2.51 & 2.33 & 1.79 & $\mathbf{2 . 2 1}$ \\
Column mean & $\mathbf{2 . 4 2 ^ { \mathrm { a } }}$ & $\mathbf{2 . 1 2 ^ { \mathrm { a } , \mathrm { b } }}$ & $\mathbf{1 . 5 8 ^ { \mathrm { b } }}$ & \\
\hline
\end{tabular}

*Assessed using a 10 point scale, with 10 being "I would definitely participate even if I was not paid".

Significance: the main effect of risk level is significant $(p<0.05)$ Within the column means, means without a common superscript are significantly different at the 0.05 level using Dunn's Method (Bonferroni)

\section{DISCUSSION}

This study provided empirical data on two ethical concerns often raised about the payment of research subjects; namely, that payments could (1) unduly induce subjects into taking part in a study that they would not participate in otherwise (by blinding the prospective subject to risks), or (2) cause subjects to conceal information that would disqualify them from the study. This study suggests that monetary payment increases respondents' willingness to participate in research regardless of the level of risk; higher levels of payment make respondents more willing to participate, even if the study is relatively risky. However, higher monetary payments, at least in this study, did not appear to blind respondents to risks. For example, the high risk study received similar risk ratings for all three levels of monetary payment. These group level findings may not apply to all individuals; thus, this finding does not alleviate all ethical concerns regarding the payment of research subjects. Using a subjective interpretation of influence, ${ }^{37}$ what is a due inducement for one individual maybe undue for another. Clearly, more research is needed to determine when monetary payment is an undue inducement. $^{12}$

This study also showed that higher levels of monetary payment may influence subjects' behaviours regarding concealing information about restricted activities. If such activities were actually engaged in, the results of the hypothetical studies may have been distorted (that is, alcohol, caffeine, medications, herbal products may all affect the pharmacokinetics of a study drug). However, findings from this study suggest that this effect may be more likely to occur in lower risk studies. By contrast, monetary payments did not have a significant effect on respondents' propensity to neglect to tell researchers when they experience negative consequences from study participation. These two findings suggest that monetary payments may be less likely to jeopardise the well being of subjects than the integrity of

Table 4 Adjusted cell and marginal means (dependent variable: propensity to neglect to tell about restricted activities*)

\begin{tabular}{|c|c|c|c|c|}
\hline \multirow[b]{2}{*}{ Payment level } & \multicolumn{3}{|c|}{ Risk level } & \multirow[b]{2}{*}{ Row mean } \\
\hline & Low & Medium & High & \\
\hline $\begin{array}{l}\$ 350 \\
\$ 800 \\
\$ 1800 \\
\text { Column mean }\end{array}$ & $\begin{array}{l}2.13 \\
3.12 \\
3.61 \\
2.95\end{array}$ & $\begin{array}{l}2.80 \\
2.60 \\
3.55 \\
2.98\end{array}$ & $\begin{array}{l}3.15 \\
3.08 \\
3.36 \\
3.20\end{array}$ & $\begin{array}{l}2.69^{c} \\
2.93^{c, d} \\
3.51^{d}\end{array}$ \\
\hline
\end{tabular}

*Assessed using an 8 item scale and transformed to a 1-10 scale, with higher scores indicating higher propensity.

Significance: the main effect of payment level is significant $(p<0.05)$ Within the row means, means without a common superscript are significantly different at the 0.05 level using Dunn's Method (Bonferroni).
Table 5 Adjusted cell and marginal means (dependent variable: propensity to neglect to tell about negative effects*)

\begin{tabular}{lllll}
\hline & \multicolumn{2}{l}{ Risk level } & \\
\cline { 2 - 4 } Payment level & Low & Medium & High & Row mean \\
\hline$\$ 350$ & 2.44 & 2.77 & 2.54 & $\mathbf{2 . 5 8}$ \\
$\$ 800$ & 3.34 & 2.01 & 1.94 & $\mathbf{2 . 4 3}$ \\
$\$ 1800$ & 3.62 & 2.75 & 2.31 & $\mathbf{2 . 8 9}$ \\
Column mean & $\mathbf{3 . 1 3 ^ { \mathrm { a } }}$ & $\mathbf{2 . 5 1 ^ { \mathrm { a } , \mathrm { b } }}$ & $\mathbf{2 . 2 6 ^ { \mathrm { b } }}$ & \\
\hline
\end{tabular}

*Assessed using a 2 item scale and transformed to a 1-10 scale, with higher scores indicating higher propensity.

Significance: the main effect of risk level is significant $(p<0.05)$.

Within the column means, means without a common superscript are significantly different at the 0.05 level using Dunn's Method (Bonferroni).

the research-not an insignificant issue. The latter is consistent with both observation ${ }^{8}$ and empirical evidence. ${ }^{38}$

\section{LIMITATIONS OF THE PRESENT STUDY AND FUTURE RESEARCH}

Several limitations of this study point to the need for additional research with respect to the payment of research subjects. The study was hypothetical in nature; behavioural intentions rather than actual behaviours were assessed. Similarly, respondents read documents on their own; there was no additional verbal explanation provided by a clinical investigator.

Another limitation concerns the monetary payment manipulation. As discussed in the methods section, respondents read that payment was in return for time, effort, and travel expenses. Only the amount of money was manipulated; no effort was made to manipulate what the money was for. Macklin ${ }^{2}$ provides a discussion of the purposes for paying subjects and Russell, Moralejo and Burgess ${ }^{19}$ note that respondents in their study distinguished between various reasons for paying subjects. Some IRBs restrict what monetary payments can be used for (for example, prohibition of completion bonuses, no payment for the assumption of risk). ${ }^{12}$ Given this information, future studies should focus not only on the amount of payment, but its purpose. Additionally, forms of payment other than money raise ethical concerns ${ }^{8}$ and should also be the subject of empirical research.

The results of the present study are based on the responses of pharmacy students. Although pharmacy students are often targeted to participate in clinical studies like the ones described in the recruitment notices and informed consent forms, the results of the present study are not generalisable to all groups who participate in this type of research. Students do not represent all healthy individuals who volunteer for research. Additional research examining the effects of

Table 6 Adjusted cell and marginal means (dependent variable: risk rating ${ }^{*}$ )

\begin{tabular}{lllll}
\hline & \multicolumn{2}{l}{ Risk level } & \\
\cline { 2 - 4 } Payment level & Low & Medium & High & Row mean \\
\hline$\$ 350$ & 1.53 & 3.27 & 6.23 & 3.68 \\
$\$ 800$ & 1.54 & 2.94 & 6.60 & 3.70 \\
$\$ 1800$ & 1.41 & 2.48 & 6.41 & 3.43 \\
Column mean & $\mathbf{1 . 5 0 ^ { \mathrm { a } }}$ & $\mathbf{2 . 8 9 ^ { \mathrm { b } }}$ & $\mathbf{6 . 4 1 ^ { \mathrm { c } }}$ & \\
\hline
\end{tabular}

*Assessed using a 5 item scale and transformed to a 1-10 scale, with higher scores indicating higher risk ratings.

Significance: the main effect of risk level is significant $(p<0.05)$. Within the column means, means without a common superscript are significantly different at the 0.05 level using Dunn's Method (Bonferroni). 
monetary payments on the decision making of other groups of healthy volunteers is warranted.

The hypothetical studies for all three risk levels were designed for healthy volunteers. Some have argued for a distinction between the payment of patients and the payment of healthy subjects. ${ }^{39}$ Dickert and Grady ${ }^{40}$ note that "there is no inherent reason to treat patients and healthy subjects differently with respect to payment" but note the lack of empirical data. The added dimension of "hope for benefits" in patients enrolling in research studies may alter the effect of monetary payments on decisions in ways that are different from healthy volunteers. Thus, future research should be directed at exploring the effects of paying patients.

Finally, impoverishment of research subjects is often considered in normative ethical discussions of the use of monetary payments in research. Although income and subjective discretionary income were collected in this study, the cell sizes were too small and too disparate to make any conclusive statements. Is the effect of monetary payment on willingness to participate different for members of different socioeconomic groups? Do members of different socioeconomic groups evaluate risk differently at different levels of payment?

\section{CONCLUSION}

Although this study may diminish some concerns regarding whether monetary payments blind research subjects to potential risks, the findings also suggest that monetary payments may lead to reductions in the integrity of a study's findings, especially for studies of lower risk. Certainly, this study does not provide a definitive answer to the question of whether monetary payments to research subjects should be prohibited. No single study can completely support or repudiate this position. There is a definite need for additional research to further examine this issue, especially as it relates to impoverished individuals. We hope that this paper will stimulate not only future research but also discussion about appropriate research policies and procedures.

\section{ACKNOWLEDGEMENTS}

We are grateful to the following individuals for their help in distributing and collecting materials: Ms Tina Penick Brock (University of North Carolina), Dr Kem Krueger (Auburn University), Dr Lon Larson (Drake University), Dr Donna West (University of Arkansas for Medical Sciences), Dr Noel Wilkin (University of Mississippi), and Dr Gary Theilman (University of Mississippi). We would also like to thank Ms Diane Lindley (University of Mississippi) and Dr Rexann Pickering (Methodist Healthcare-Memphis, TN) for reviewing our informed consent forms and recruitment notices. We are grateful to Dr Thomas Lombardo (University of Mississippi) for his helpful comments on the manuscript. Finally, we appreciate the thoughtful suggestions provided by the two anonymous reviewers.

\section{Authors' affiliations \\ J P Bentley, P G Thacker, School of Pharmacy, The University of Mississippi, University, MS, USA}

\section{REFERENCES}

1 Faden RR, Beauchamp TL. A history and theory of informed consent. Oxford: Oxford University Press, 1986:338-9.

2 Macklin R. On paying money to research subjects: 'due' and 'undue' inducements. IRB 1981;3:1-6.
3 Palmer WE. Monetary inducement to research participation. Pharos Alpha Omega Alpha Honor Med Soc 1985;48:26-30.

4 See reference 1:339-41.

5 Steinbock B. Coercion and long-term contraceptives. Hastings Cent Rep 1995:25:S19-S22.

6 Wilkinson M, Moore A. Inducement in research. Bioethics 1997; 11:373-89.

7 Erlen JA, Sauder RJ, Mellors MP. Incentives in research: ethical issues. Orthop Nurs 1999:18:84-7.

8 Grady C. Money for research participation: does it jeopardize informed consent? Am J Bioeth 2001;1:40-4.

9 Office for Human Research Protections. Institutional Review Board Guidebook. http://ohrp.osophs.dhhs.gov/irb/irb_guidebook.htm laccessed 11 April 2001).

10 See reference 3:27.

11 Dickert N, Grady C. What's the price of a research subject? Approaches to payment for research participation. N Engl J Med 1999;341:198-203.

12 Dickert N, Emanuel E, Grady C. Paying research subjects: an analysis of current policies. Ann Intern Med 2002;136:368-73.

13 U.S. Food and Drug Administration. Payment to research subjects. Information sheets. Guidance for Institutional Review Boards and Clinical Investigators, 1998 Update. http://www.fda.gov/oc/ohrt/irbs/ toc4.html\#payment (accessed 7 February 2003).

14 McNeill P. Paying people to participate in research: why not? A response to Wilkinson and Moore. Bioethics 1997;11:390-6.

15 See reference 14:394

16 Brody BA. The ethics of biomedical research: An international perspective. Oxford: Oxford University Press, 1998:44.

17 See reference 3:30

18 Wilkinson M, Moore A. Inducements revisited. Bioethics 1999;13:114-30.

19 Russell ML, Moralejo DG, Burgess ED. Paying research subjects: participants' perspectives. J Med Ethics 2000;26:126-30.

20 Aby JS, Pheley AM, Steinberg P. Motivation for participation in clinical trials of drugs for the treatment of asthma, seasonal allergic rhinitis, and perennial nonallergic rhinitis. Ann Allergy Asthma Immunol 1996;76:348-54.

21 Fry C, Dwyer R. For love or money? An exploratory study of why injecting drug users participate in research. Addiction 2001;96:1319-25.

22 Bigorra J, Banos JE. Weight of financial reward in the decision by medical students and experienced healthy volunteers to participate in clinical trials. Eur J Clin Pharmacol 1990;38:443-6.

23 Cunny KA, Miller HW. Participation in clinical drug studies: motivations and barriers. Clin Ther 1994;16:273-82.

24 Hermann R, Heger-Mahn D, Mahler M, et al. Adverse events and discomfort in studies on healthy subjects: the volunteer's perspective. A survey conducted by the German Association for Applied Human Pharmacology. Eur J Clin Pharmacol 1997:53:207-14.

25 Casarett D, Karlawish J, Asch DA. Paying hypertension research subjects: fair compensation or undue inducement? J Gen Intern Med 2002;17 651-3

26 Sears JM. The payment of research subjects: ethical concerns. Oncol Nurs Forum 2001;28:657-63.

27 See reference 11:202.

28 See reference 12:373

29 James JM, Bolstein R. The effect of monetary incentives and follow-up mailings on the response rate and response quality in mail surveys. Public Opin $Q$ 1990;54:346-61.

30 Office for Human Research Protections. Tips on informed consent. http:// ohrp.osophs.dhhs.gov/humansubjects/guidance/ictips.htm (accessed 11 April 2001).

31 US Food and Drug Administration. A guide to informed consent. Information sheets. Guidance for Institutional Review Boards and Clinical Investigators, 1998 Update. http://www.fda.gov/oc/ohrt/irbs/informedconsent.html (accessed 16 February 2001).

32 US Department of Labor, Bureau of Labor Statistics. Average hourly and weekly earnings of production or nonsupervisory workers on private nonfarm payrolls by industry. http://stats.bls.gov:80/news.release/empsit.tl3.htm (accessed 9 August 2001).

33 Hair JF, Anderson RE, Tatham RL, et al. Multivariate data analysis, 5th ed. Upper Saddle River, NJ: Prentice-Hall, 1998:117.

34 Nunnally JC. Psychometric theory, 2nd ed. New York: McGraw-Hill, 1978.

35 Bruning ER, Kovacic ML, Oberdick LE. Segmentation analysis of domestic airline passenger markets. JAMS 1985;13:17-31.

36 Keppel G. Design and analysis: A researcher's handbook, 3rd ed. Upper Saddle River, NJ: Prentice Hall, 1991:283.

37 See reference 1:260-1.

38 Tomporowski PD, Simpson RG, Hager L. Method of recruiting subjects and performance on cognitive tests. Am J Psychol 1993;106:499-521.

39 Lemmens $T$, Elliott C. Guinea pigs on the payroll: the ethics of paying research subjects. Account Res 1999;7:3-20.

40 See reference 11:199. 